\title{
Cyberbulling as a new form of a threat: a physiological, psychological and medicinal aspects
}

\author{
Mikhail N. Mikhaylovsky ${ }^{1}$, Irina V. Lopatkova ${ }^{2}$, Nataliya M. Komarova ${ }^{3}$, Evgeniya O. Rueva ${ }^{4}$, Konstantin S. Tereschuk ${ }^{5}$, \\ Anna V. Emelyanenkova ${ }^{6}$
}

\begin{abstract}
Objectives: Our goal is to study the effect of the phenomenon of cyberbullying on teenagers and teenagers at the physiological, psychological and medical level, as well as to determine the content of medical and psychological prevention of cyberbullying. The goal of the study determined our objectives: to determine the theoretical approaches to the substantiation of the phenomenon of "cyberbullying"; to identify methods and means of assistance to a teenager who has become a victim of cyberbullying at the physiological, psychological and medical level; to describe the activities of a specialist to provide assistance and follow-up for a teenager who has become a victim of cyberbullying.

Materials: In solving these tasks, the following research methods were used: system analysis and synthesis of international and domestic literature on the research problem; systematization of facts; the analysis of regulations; psychophysiological diagnostics (tepping-test, kopping-test, Dot cancellation test), psychological research methods (survey in the form of questioning, testing).

Results: We can draw a conclusion about the causal interdependence of psychological, physiological and clinical and the consequences of cyberbullying for teenagers. Most teenagers who were victims of cyberbullying have a high and medium level of anxiety (which indicates their inherent increased anxiety, which may be accompanied by depression, isolation, unwillingness to maintain existing social contacts and make new ones); a decrease in activity and, as a result, a decrease in school performance; a high level of frustration (which is accompanied by such negative emotions as disappointment, irritation, a teenager has a general sense of wreck); high and medium level of constriction (teenagers with a high level of constriction have significant difficulties in the process of adaptation, which significantly affects the social side of their lives and significantly affects the resolution of emerging problems).

Conclusions: When providing assistance to teenagers clinical psychologist need to rely on the following principles: systemic; subject-subjectivity, or communication; adaptation and endurance; safety and reliability. These principles will work successfully if the following individual and group methods of psychotherapy are used: creating a new cognitive model of life activity; affective reassessment of traumatic experience; restoration of a sense of self-esteem and the ability to exist in the world; colloquial psychotherapy (logotherapy, which involves the coincidence of verbal argumentation and the internal state of a teenager, leading to self-realization, when a teenager focuses on personal experiences, thoughts, feelings, desires); game therapy, art therapy, music therapy (through the perception of music), vocal therapy (through singing); kinesitherapy and psychodrama.
\end{abstract}

Keywords: deviant behavior, cyberbullying, diagnosis, mental and psycho-psychological health, social and biological factors, emotional disorders, prevention, correction

\section{INTRODUCTION}

At present, the phenomenon of cyberbullying is discussed by specialists in connection with the increasing incidence of suicide among teenagers and teenagers. The spread of cyberbullying is associated with the development of Internet technologies and an increase in cases of Internet aggression. This type of aggression is widespread among teenagers and teenagers, since the offender's identity is anonymous, as a result of which teenagers prone to violent behavior become more active.

\footnotetext{
1 Sechenov First Moscow State Medical University, Moscow, Russia.

2 Federal State Budgetary Educational Institution of Higher Education, «Moscow Pedagogical State University», Moscow, Russia.

3 Moscow Region State University, Moscow, Russia.

4 Plekhanov Russian University of Economics, Moscow, Russia.

5 Russian State Social University, Moscow, Russia.

6 Ulyanovsk State University, Ulyanovsk, Russia.
}

\section{Correspondence: Anna V. Emelyanenkova \\ Ulyanovsk State University, Ulyanovsk, Russia. \\ E-mail:annemel@mail.ru}

Received: 15 May 2019, Accepted: 30 Oct 2019

(C) 2019 by the authors; licensee Modestum Ltd., UK. This article is an open access article distributed under the terms and conditions of the Creative Commons Attribution License (http://creativecommons.org/licenses/by/4.0/). 
The manifestation of aggression remotely does not enable one to see the reaction of the victim and the influence of his act, does not cause a feeling of empathy. All electronic means of communications are available, which contributes to the speed of transmission and relay of information.

In Russian science, the process of cyberbullying has been focused on relatively recently, although the problem is extremely acute. According to psychologists, in Russia every third child is subjected to cyberbullying. The extent of the phenomenon can also be judged from the news, which covers incidents related to severe cyberbullying, that is, associated with physical violence.

In recent years, the phenomenon of cyberbullying has received a lot of attention among researchers, work has been carried out to study, diagnose and prevent it. The names of foreign scientists, for example, Bill Belsay (1), who first defined the concept of cyberbullying and is the creator of the website www.bullying.org, are best known in this field. Mr. Berson et al. (2) is exploring new risks of violence in the digital age. Ybarra determines the connection between depressive states of teenagers and Internet bullying (3). Keith and Martin are developing a culture of behavior on the Internet (4).

In Russia, Naidyonova (5) and Osipov (6) are studying this problem. They identify the effects of cyberbullying and develop ways to protect against it. Parfentiev interprets cyberbullying from the point of view of the legal framework and draws attention to the development of Internet security (7).

Our goal is to study the effect of the phenomenon of cyberbullying on teenagers and teenagers at the physiological, psychological and medical level, as well as to determine the content of medical and psychological prevention of cyberbullying. The goal of the study determined our objectives: to determine the theoretical approaches to the substantiation of the phenomenon of "cyberbullying"; to identify methods and means of assistance to a teenager who has become a victim of cyberbullying at the physiological, psychological and medical level; to describe the activities of a specialist to provide assistance and follow-up for a teenager who has become a victim of cyberbullying.

At the physiological and medicine levels, one should consider the medical consequences of cyber bullying. Cyberbullying affects the functioning of the whole body. Depressions, stresses arise, as a result it leads to a decrease in immunity; frequent complaints of headaches, pain in the heart, nausea, fatigue, poor sleep, sometimes insomnia; impaired memory and attention, speech defects or nerve tics (blinking); poor appetite. In especially severe cases, stress experienced through cyberbullying can delay or even stop psychic development. Such a person can never get rid of psychological trauma. After such experience, a child may have heart or infectious diseases, stomach ulcer, neurosis. It can trigger off the development of chronic diseases (asthma, diabetes mellitus). Blood glucose levels often increase with physical and mental injuries.

In solving these tasks, the following research methods were used: system analysis and synthesis of international and domestic literature on the research problem; systematization of facts; the analysis of regulations; psychophysiological diagnostics, psychological research methods (survey in the form of questioning, testing).

\section{METHODOLOGICAL FRAMEWORK}

The risks and threats that minors face on the Web today are diverse. Along with the threats of developing Internet addiction, an interest of children in playing games on the Internet, the threats of financial fraud, new threats associated with communication on social networks are gaining momentum today, indicating a targeted destructive impact on the immature psyche of schoolchildren. These are also glaring cases of mass suicides among schoolchildren - members of the same groups on social networks, and the problems of bullying and grooming on the network, the problems of recruiting to closed communities, including extremist and other dangerous groups, etc. High rates of their spread require the immediate adoption of all possible measures to counter these threats. The state and society are actively developing and implementing a system of legal measures designed to limit the distribution of dangerous content on the network, and to strengthen control over the information posted. State and public organizations conduct regular monitoring of the network. However, only prohibitive measures do not guarantee full protection of children and teenagers from the threats associated with their browsing on the Internet for many hours. It seems evident that it is necessary to provide special psychological and pedagogical prevention of the negative impact connected with Internet activity of schoolchildren on their mental and psychological health, personal well-being, which would combine the efforts of all interested institutions, and, above all, educational organizations and families. Taking account that the risk factors of the Internet space are a relatively new type of risk factors for the social adaptation of minors, the scientific and methodological support to provide preventive work has so far been clearly insufficient. The psychological literature presents studies of Internet addiction, factors and causes that influence their distribution, approaches to correction (8, 9). Relatively recently, studies have appeared on other risks of the Internet space, the children and adults' perceptions of 
the Internet, their awareness of the means and methods of protection in the Internet space $(10,11)$. However, the extent of attention to the problem from different areas of science, the degree of its elaboration, remains disproportionate to rates of risks spreading, their diversity and the severity of the harm. Under these conditions, the task of developing scientific and methodological foundations to prevent Internet threats appears to be important.

The teen years are one of the most important periods in the development of a person. A teenager is no longer a child, but not yet an adult. He is actively involved in adult life, forms his identity and masters various social roles. The teen years (from 11-12 to 16-17 years of age) is a period of growing up, psychological and physical changes, physiological restructuring of the body. Such changes cause frequent mood swings, emotional instability and impulsivity. Teenagers sometimes tend to show depression, restlessness and a low concentration of attention and irritability. Teenagers are characterized by aggression and anxiety, conflicts with adults. A teenager realizes that the world is not perfect, finds many shortcomings in himself. Parents do not notice how an affectionate child turns into an irritable teenager who behaves disrespectfully towards them and people around him. It is very important for parents to maintain close trusting relationships with the child, since right now their character, worldviews and value orientations are being formed. Many psychological problems arise: self-doubt, instability, inadequate self-esteem, often underestimated, which is very typical of a teenager. Despair, inability to explain one's feelings, resentment at undeserved reproaches, loss of trust can become a cause of teenagers' deviant behavior.

Deviant behavior is a deviation from the norms accepted in society. Deviance is manifested in a violation of the process of self-actualization, evasion of moral and aesthetic control over one's own behavior (10).

In pedagogical literature, deviant behavior was considered from the point of view of the age-related approach and the social activity of schoolchildren (12-16).

The psychological and social aspect of deviant behavior is analyzed in the works of Belicheva and Badmayev. The authors propose characteristics of deviant behavior as a variant of social maladaptation, inadequate behavior to the norms and requirements of society (17).

In the studies conducted by Feldstein (18) a classification of deviant behavior types is proposed which is based on offenses among teenagers:

- offenders with persistent socially negative needs;

- children with deformed needs;

- children with a conflict between deformed and positive needs;

- children with slightly deformed needs, weak-willed;

- children who accidentally step on the path of crime.

Mendelevich (19) identifies 5 types of deviant behavior:

- delinquent behavior - violating social and legal norms.

- addictive - behavior in which there is a change in the mental state through the use of psychoactive substances (PAS) or through constant fixation of attention on the development and maintenance of intense emotions (for example, religious or sports fanaticism, Internet addiction, pathological addiction to gambling, etc.).

- patho-characterological - the type of deviation is due to the process of education,

- psychopathological - manifestations of mental illness.

- based on hyper abilities - due to the presence of special abilities of the individual.

The following causes of social deviant behavior of teenagers are pointed out in the domestic literature:

- a dysfunctional family.

- personal characteristics (age, characterological, mental).

- disadaptation at school.

- influence of asocial environment (20-25).

The following is identified among the main forms of teenage deviation:

1. Alcohol use. Teenagers commit crimes with the aim of acquiring alcohol; teenagers who drink alcohol can be involved in criminal activities, which are organized by adults. The main reasons for alcohol drinking by teenagers are the desire for self-affirmation, possible pastime, avoidance of reality.

2. Drug addiction - addiction to substances that cause a state of altered consciousness. These substances are different in composition, in action on the human body. Drug use is irreversibly harmful to the body, and a person who uses drugs is dangerous to society as a whole.

3. Juvenile delinquency. Teenagers seek to seize other people's values and money to buy things, electronic devices. 
4. Aggression. Acts of breaking the law are often accompanied by aggressive actions. Aggression of a teenager can be directed towards others. A special kind of aggression is that directed at oneself (self-mutilation, suicide). Suicidal behavior is one of the dangerous forms of manifestation of teenagers' deviant behavior. Suicidal behavior at this age may be demonstrative, with a possible desire to escape from problems.

5. Bullying is repeated aggressive actions of some people in relation to others that have taken place for a long time.

6. Cyber bullying. Contemporary teenagers spend a lot of time on the Internet, which can lead to the formation of Internet addiction. This leads to a lack of desire and eagerness to communicate with peers, there is asociality, a loss of a sense of reality. By manipulating the minds of teens, they are invited to dangerous online games, communities and groups on the Internet. One of the relevant forms of deviant is cyber bullying - baiting a person on the Internet. Teenagers write and receive offensive letters; bullying is carried out through social networks, chats and blogs (26-30).

Cyber bullying is a form of deviant behavior that teenagers often demonstrate. The consequences of cyber bullying can be dangerous not only for the victim that a psychological trauma is inflicted on, but also for those who commit this crime.

The book "Cyber bullying: Bullying in the Digital Age" (by Kowalski R., Limber S. and Agatston P.) presents the forms of cyber bullying (31):

- Flaming - emotional statements addressed to each other in social networks.

- Bashing - repeated offensive messages aimed at the victim (for example, endless texts and calls).

- Slander - the dissemination of humiliating false information.

- Imposture - transformation into another person through an account in social networks, using someone else's password.

- Alienation (isolation) from online communities can occur in any password-protected environments or through removal from the "friends list".

A theoretical analysis of the literature made it possible to identify the main causes of deviant behavior among teenagers:

1. Biosocial - attraction to the opposite sex, early puberty.

2. Socio-psychological - the desire for emotional intimacy, unification with peers through negative actions: drinking alcohol, committing joint offences.

3. Social maladaptation - the disruption of social adaptation, conflicts with parents, teachers, peers (32-34).

Contemporary teenagers try to find comfort in deviation, perceive illegal acts as socially acceptable and orient to them in the process of life self-determination. An important task that is set before the family, society, educational organizations is to prevent and overcome the factors that can cause deviant behavior in teenagers. The effectiveness of prevention is ensured by the joint activities of educational organizations, medical institutions, the family and society as a whole. Guidelines on the prevention of deviant behavior among teenagers:

1. Timely diagnosis - it is important to conduct a comprehensive primary psychological diagnosis aimed at identifying personal characteristics, moral position, relationships in the group in order to identify teenagers of the risk group for further support and follow-up.

2. Raising the parents' psychological and pedagogical competence. It is the family that is the basis of moral upbringing of a teenager. Value orientations and moral qualities are formed in the family. It is important to raise the psychological literacy of parents on education issues, signs of deviant behavior, forms of dialogue with the child.

3. Increasing the role of educational institutions in the prevention and overcoming of deviations among teenagers. It is important that teachers increase their professional knowledge on the prevention of deviant behavior, so they could identify primary symptoms and provide psychological and pedagogical support to a teenager.

4. The interaction between the family and the educational institutio to increase the level of the educational process. Holding joint events (training programs, master classes, discussions) for children and parents, teachers in order to prevent conflict situations.

5. Positive prevention through the media, the Internet. Involving children in additional education, socially useful activities, volunteering.

Work to prevent deviant behavior should be based on certain principles:

1. Voluntary basis. If we want to make prevention and correction of deviant behavior effective, it is required to create conditions for the voluntary participation of teenagers in primary and secondary diagnostic testing, the work of remedial groups. 
2. Awareness. Only conscious recognition of the problem, the desire to change to ensure the effectiveness of preventive and corrective work. It is important to create the conditions for the teenager to see himself in the future, being completely different, with different positive behavior.

3. Expediency. Only a comprehensive medical-psychological-psychiatric examination will allow one to properly build work to correct deviation. The presence of clinical problems can lead to the fact that when eliminating one form of deviant behavior, a new one appears.

4. Positive practice. When working with teenagers, it is important to guide them to the best qualities, the presence of personal uniqueness and value in them, for the family and society. It is important for a teenager to know that he is needed, appreciated, even if his behavior is not always correct.

The main conditions for the effectiveness of work with deviant behavior among teenagers are: activities in all areas of work to address deviant behavior of a teenager, his family, an educational institution, his social environment, the integration of moral and legal aspects; integration of an individual and collective approach to socio - psychological work (35).

\section{MATERIALS AND METHODS}

Our goal is to study the effect of the phenomenon of cyberbullying on teenagers and teenagers at the physiological, psychological and medical level, as well as to determine the content of medical and psychological prevention of cyberbullying. The goal of the study determined our objectives: to determine the theoretical approaches to the substantiation of the phenomenon of "cyberbullying"; to identify methods and means of assistance to a teenager who has become a victim of cyberbullying at the physiological, psychological and medical level; to describe the activities of a specialist to provide assistance and follow-up for a teenager who has become a victim of cyberbullying.

In solving these tasks, the following research methods were used: system analysis and synthesis of international and domestic literature on the research problem; systematization of facts; the analysis of regulations; psychophysiological diagnostics, psychological research methods (survey in the form of questioning, testing).

Research on the number of teenagers that suffered from cyberbullying and the study of their conditions was carried out at a secondary school in Moscow.

The work done consisted of the following steps:

1. determining the number of teenagers who suffered from cyberbullying;

2. diagnosis of physiological and psychological conditions of teenagers;

3. determining the level of activity of teenagers who became victims of cyberbullying;

4. the organization of the process of assistance for a teenager who has become a victim of cyberbullying in school conditions, together with a social pedagogue.

Our study involved 88 teenagers studying in two grades, eighth and ninth, aged 13-14.

At the first stage, the number of teenagers who had suffered from cyberbullying was determined with the use of an anonymous questionnaire to identify the percentage of teenagers who had suffered from cyberbullying to the number of those who had not suffered, in order to determine the extent of the existing problem. According to the study, all 88 teenagers were active Internet users and whose accounts were registered on the popular social networks VKontakte, Odnoklassniki, Facebook, MySpace, etc. The time that they spent communicating on the Internet ranged from 5 to 9 hours a day.

\section{RESULTS AND DISCUSSION}

As a result of the survey, it was found that out of 88 teens 47 at least once became victims of cyberbullying. Of these, 12 themselves proved to be cyberbullies, because they believe that aggression should be counteracted with aggression. Fifteen people were victims of cyberbullying and would never act as cyberbullies, because they understand that this insults another person and can lead to irreparable consequences. Sixteen teens have never been abused online or have subjected others to it; 4 teenagers were cyberbullies, as this reinforces their authority among friends and they find it funny.

More often, teenagers are exposed to the following types of cyberbullying: flaming - the exchange of short emotional replies between two or more people, unfolding on Web pages; baiting - repeated offensive messages directed at the victim (for example, hundreds of messages, constant calls), overloading personal communication channels; slander - the dissemination of offensive and untruthful information (text messages, photos, songs); imposture - the baiter positions 
himself as a victim using the victim's password to access his account in social networks, blogs, etc., or creates a page on behalf of the victim; happy slapping - videos with scenes of violence, beatings, kicks, humiliating the victim; cybertracking - covert tracking of a victim to organize an assault.

Teenagers rarely confide their problems to anyone, and cyberbullying is generally one of those problems that they very rarely tell parents or teachers, because they are shy and afraid of publicity. More often, if a teenager needs to talk, he confides in a friend. Answer options "told a teacher, social pedagogue", "asked for support via the helpline," were not chosen by any teenager surveyed.

Teenagers who proved to be cyberbullies answered the question "Why are you doing this?" The frequently answered: "For fun, it's funny" ( 6 out of 11 teenagers); 2 people chose the answer "It increases my authority"; 3 teenagers said they were doing it out of personal dislike.

At the second stage, we diagnosed the psychophysiological conditions of teenagers. Using the "Technique for the diagnosis of self-assessment of mental states by G. Eysenck (36)," we determined the level of anxiety, frustration, aggressiveness and constriction. This test was anonymous, but due to the fact that the questionnaires and tests were stapled, we were able to track the condition of teenagers and their interrelationship with cyberbullying.

Let us compare the results obtained in the study of the emotional states of teenagers who were victims of cyberbullying and teenagers who have never encountered cyberbullying. Of the teenagers who became victims of cyberbullying, 40\% showed a high level of anxiety (excitement, increased anxiety in various situations, poor sleep, expectation of troubles from others). Even minor life difficulties, as well as troubles that have not yet occurred, frighten such teenagers. Fifty-five per cent of test participants have an average level of anxiety, within normal limits, and $5 \%$ of teenagers are not anxious. Forty-five per cent of teenagers who have not experienced cyberbullying have an average level of anxiety, and 55\% of them are not anxious. Consequently, they are less likely to experience increased anxiety, they have less causeless fears in various social situations. They perceive others more friendly.

In the study of frustration, we obtained the following results: $50 \%$ of cyberbullying victims showed a high level of frustration, indicating that these teenagers in real or fictional situations in which their desire cannot be fulfilled, experience a feeling of frustration, irritation or despair. Such teenagers feel bewildered by the difficulties that arise, they have reduced self-esteem, and there is a tendency to avoid failure. Thirty per cent of teenagers have an average level of frustration, which is acceptable, and $20 \%$ have a low level of frustration. They adequately assess the difficulties encountered, without blaming themselves for failure, have a high self-esteem. Among teenagers who have not experienced cyberbullying, $60 \%$ have a low level of frustration, $30 \%$ have an average and only $10 \%$ have a high level of frustration. The data indicates that teenagers who were victims of cyberbullying are not self-confident, more vulnerable and sensitive to difficult life situations.

The data that we obtained on the "aggressiveness" scale indicates that $40 \%$ of teenagers who were victims of cyberbullying have a low level of aggressiveness, which indicates harmlessness and inability to stand up for themselves. Fifty per cent of teenagers have an average level of aggressiveness; they like to argue and defend their point of view. A high level of aggressiveness was found in $10 \%$ of teenagers who were inclined to defend their point of view, even knowing that they were wrong, interrupt the interlocutor and leave the last word for themselves. Teenagers who have not experienced cyberbullying in $75 \%$ have an average level of aggressiveness, which is normal for teenagers, and the remaining $25 \%$ have a low level of aggressiveness.

Analyzing the data obtained on the "constriction" scale, we see that $20 \%$ of teenagers have a high level of constriction, they can hardly tolerate any changes in their plans and can be overly focused on certain objects and events; Forty-five per cent have an average level of constriction, which is acceptable. A low level of constriction was found in $25 \%$ of teenagers, this suggests that they do not have concentration on objects and situations, they are easier to change plans and habits, most likely they forget everything. Among teenagers who did not experience cyberbullying, only $30 \%$ showed an average level of constriction, while the remaining $70 \%$ showed a low level of constriction.

We can draw a conclusion about the causal interdependence of psychological and social characteristics and the consequences of cyberbullying for teenagers. Most teenagers who were victims of cyberbullying have a high and medium level of anxiety (which indicates their inherent increased anxiety, which may be accompanied by depression, isolation, unwillingness to maintain existing social contacts and make new ones); a decrease in activity and, as a result, a decrease in school performance; a high level of frustration (which is accompanied by such negative emotions as disappointment, irritation, a teenager has a general sense of wreck); high and medium level of constriction (teenagers with a high level of constriction have significant difficulties in the process of adaptation, which significantly affects the social side of their lives and significantly affects the resolution of emerging problems). 
Having a high level of constriction, a teenager hardly changes his behavior or idea of something, and it is much easier for him to wait until the situation is resolved without his participation. Consequently, a teenager who was a victim of cyberbullying is subject to personality suppression. The higher the level of anxiety, frustration and stiffness in a teenager, the less comfortable he feels. Regarding the level of aggressiveness, we can say that most teenagers who were victims of cyberbullying have an average and low level of aggressiveness, they are calm, do not feel superior to the people around them, and do not tend to suppress others.

When providing assistance to teenagers, social pedagogues, psychologists need to rely on the following principles: systemic; subject-subjectivity, or communication; adaptation and endurance; safety and reliability.

These principles will work successfully if the following individual and group methods of psychotherapy are used: creating a new cognitive model of life activity; affective reassessment of traumatic experience; restoration of a sense of self-esteem and the ability to exist in the world; colloquial psychotherapy (logotherapy, which involves the coincidence of verbal argumentation and the internal state of a teenager, leading to self-realization, when a teenager focuses on personal experiences, thoughts, feelings, desires); game therapy, art therapy, music therapy (through the perception of music), vocal therapy (through singing); kinesitherapy (dance therapy, corrective rhythm, psycho-gymnastics therapeutic effect with movements); bibliotherapy (corrective effect by reading), fairy tale therapy (composing stories); image therapy (impact through the image, theatricals): puppet therapy, figurative-role dramatization, psychodrama; visual art therapy (pictorial therapy) - correctional impact by means of fine art: drawing, modeling, decorative and applied art; psycho-gymnastics (interaction is based on motor expression, facial expressions, pantomime). The methods are aimed at achieving two goals: reducing stress and reducing the emotional distance in members of the group, as well as developing the ability to express feelings and desires. For example, stress relief exercises consist of the simplest movements: "I am walking on water", "on hot sand", "I am hurrying to school". The combination of facial expressions, gestures, movements creates a more complete opportunity to express and convey their feelings and intentions without words; through discussion of the film, as close as possible to the life situation of a teenager, we learn to analyze and model their actions in a similar situation (37-40).

\section{CONCLUSION}

To sum up, it should be pointed out that deviant behavior of teenagers is thought of as antisocial actions, offences. The latter forms are usually not pathological in nature and are expected to disappear with maturation. Currently, the state is working to improve the status of the family, improve the quality of relations in society, between generations. The manifestation of disorders of behavior among teenagers depends on the interaction of many factors: sociopsychological, psychopathological and personality-dynamic ones.

The personality traits of teenagers serve as one of the signs of deviant behavior. Personal characteristics are also affected by family education and the milieu. It usually comprises such qualities as anxiety, low self-esteem and others.

Teachers and parents often make serious mistakes in teaching and upbringing that can provoke deviant behavior. Instead of conducting dialogue, measures, restrictions, and prohibitions are introduced that make the teenager think about the "revolt", the desire to resist "sanctions". In order to avoid such mistakes, it is important to establish a trusting relationship so that the child is not afraid of reproach and criticism, but sees a friend in the parents, the teacher, who is understanding and ready to support.

\section{REFERENCES}

1. Belsey B. Cyberbullying: An emerging threat to the "always on" generation. Available at: http://www.cyberbullying.ca/pdf/feature_dec2005.pdf (Accessed January 16, 2005)

2. Berson IR, Berson MJ, Ferron JM. Emerging risks of violence in the digital age: Lessons for educators from an online study of adolescent girls in the United States. Journal of School Violence, 2002;1(2):51-71. https://doi.org/10.1300/J202v01n02_04

3. Ybarra ML. Linkages between depressive symptomatology and Internet harassment among young regular Internet users. Cyberpsychol and Behavior. Apr, 2004;7(2):247-57. https://doi.org/10.1089/109493104323024500 PMid:15140367

4. Keith S, Martin ME. Cyber-bullying: Creating a Culture of Respect in a Cyber World. Reclaiming Children \& Youth, 2005;13(4):224-8. 
5. Naidyonova L. Cyber-bullying: a dangerous virtual "bulling". Available at: http://psyfactor.org/lib/cyberbullying.htm???history=8\&sample=4\&ref=0 (Accessed October 12, 2019)

6. Osipov IS. Cyberbullying and its effects on adolescent mental health. Available at: http://www.rae.ru/forum2012/275/1643 (Accessed October 12, 2019)

7. Parfentiev U. Cyber aggressors. Children in the Information Society, 2009;2:66-7. Available at: http://detionline.eom/assets/files/journal/2/threat2_2.pdf

8. Erofeeva MA, Grinenko AV, Stanovova LA, Kosolapova NV, Mikhaylovsky MN, Rybina IA, Kochetkov IG. Motivation and motives of juvenile delinquents. EurAsian Journal of BioSciences, 2019;13:1-6.

9. Ackerman N. The role of the family in the manifestation of disorders in children. Family psychotherapy. St. Petersburg: Peter; 2008.

10. Zotova OI. Problems of deviant behavior. Psychological problems of social regulation of behavior. Moscow: Science; 2006.

11. Belichev SA. Diagnosis and correction of social maladaptation of adolescents. Moscow: Prosvet; 2013.

12. Erofeeva MA, Grinenko AV, Stanovova LA, Kosolapova NV, Mikhaylovsky MN, Rybina IA, Kochetkov IG. Motivation and motives of juvenile delinquents. EurAsian Journal of BioSciences, 2019;13:1-6.

13. Kalinina NV, Kalinin IV, Oschepkov AA, Salakhova VB, Simanovskay MA The Use of Social Resources of Inclusive Educational Environment to Cope Difficult Situations by Adolescents. Mathematics education, 2016;11(7):252736.

14. Kovaleva NB. The Role of Reflection in the Development of a Culture of Collective Creativity. Azimuth of Scientific Research: Pedagogy and Psychology, 4(13):2015;120-3.

15. Lekareva EE, Zaretskiy VV, Artamonova EG, Salakhova VB, Efimova OI, Kalinina NV. Comprehensive rehabilitation of minors with deviant and delinquent behavior: The experience of the Russian system of education. Eurasian journal of analytical chemistry. Eurasian Journal of Analytical Chemistry, 2018;13(1b):em84. https://doi.org/10.29333/ejac/102249

16. Salakhova VB, Belinskaya DB, Erofeeva MA, Ulyanova IV, Zotova LE, Khammatova RS, Mizonova OV. Modern methods of diagnosing addiction to psychoactive substances: neurophysiological aspects. Electronic journal of general medicine, 2018;15(6):94-106. https://doi.org/10.29333/ejgm/100633

17. Badmaev SA, Belicheva SA. Fundamentals of preventive psychology. Moscow: Social health of Russia; 1999.

18. Feldstein DI. Psychology of a developing personality. Moscow: Reading book on developmental psychology. Moscow: Institute of Practical Psychology, 1998.

19. Mendelevich VD. Psychology of deviant behavior: a training manual. St. Petersburg: Speech; 2008.

20. Sokolovskaya IE, Grinenko AV, Miroshkin DV, Udodov AG, Egorova EV, Diatlova EV. The Eco-Psychological Approach in the Psychological Follow-Up Program for Children with Limited Abilities. Ekoloji, 2019;107:659-64.

21. Masalimova AR, Chibakov AS. Experimental analytical model of conditions and quality control of vocational training of workers and specialists. Mathematics Education, 2016;11(6):1796-808.

22. Salakhova VB, Gnedova SB, Emelyanenkova AV, Mikhailova IV, Sedunova AS, Enyashina NG. Individual characteristics of students in the course of professional development (as exemplified by the ulyanovsk region of russia). Asian Social Science, 2015;11(3):168-75. https://doi.org/10.5539/ass.v11n3p168

23. Mukhametshin RZ, Kryukova NI, Beloborodova AV, Grinenko AV, Popova OV. Implementation of Efficient Energy Policy in Russia: Energy Consumption Monitoring and Problem Analysis. International Journal of Energy Economics and Policy, 2019;9(4):224-32. https://doi.org/10.32479/ijeep.7967

24. Salakhova VB, Oschepkov AA, Lipatova NV, Popov PV, Mkrtumova IV. Features of Social Attitudes and Value Orientations of Youths and Adolescents Prone to Auto-Aggressive Behavior. International journal of environmental \& science education, 2016;11(16):9017-25.

25. Kovaleva NB. Psycho-pedagogical Conditions of Translation of the Value of Education and the Development of Individual Educational Trajectory in Teenagers. Psychological Science and Education, 2014;19(4):64-71.

26. Kalenik EN, Salakhova VB, Mikhaylovsky MN, Zhelezniakova ME, Bulgakov AV, Oshchepkov AA. Psychophysiologic features and personal-adaptive potential of students with limited abilities. Electronic journal of general medicine, 2018;15(6):em98. https://doi.org/10.29333/ejgm/100635

27. Salakhova VB, Oschepkov AA. Peculiarities of social groups of teenagers with deviant orientation. Simbirsk Scientific Journal Vestnik, 2017;2(28):46-54. 
28. Grinenko AV, Gegel LA, Poleshchuk IA, Tutaeva DR, Pronina EV, Shchukina TV, Egorova EV. A governing and political orientation in the field of education. EurAsian Journal of BioSciences, 2019;13:1-6.

29. Oschepkov AA, Salakhova VB. Features of life situations of young people tending to deviant behavior. Simbirsk Scientific Journal Vestnik, 2016;2(24):37-41.

30. Makarova EV, Kryukova NI, Sizova ZhM, Grinenko AV, Erofeeva MA, Bukalerova LA. Divergence of Supreme Values of Russian World and Western Civilization Social and Philosophical Analysis. European Journal of Science and Theology, 2019;15(3):97-107.

31. Kowalski RM, Limber SP, Agatston PW. Cyberbullying: Bullying in the digital age (2nd ed.), Chichester: WileyBlackwell; 2011.

32. Mitin SN. Psychotherapeutic approach in the management of the development of educational systems. Simbirsk Scientific Journal Vestnik, 2016;4(26):31-9.

33. Klementovich I. Modern family: structure, specifics, educational opportunities. Parenting; 2008.

34. Moskvichev VV. Social work with minors. Experience in organizing social services. Moscow: Russian charity foundation "NAS"; 2003.

35. Salakhova VB, Bulgakov AV, Sokolovskaya IE, Khammatova RS, Mikhaylovsky MN. Substantive (Content-Related) Characteristics of Deviant Behavior as a Social and Psychological Phenomenon. International journal of environmental \& science education, 2016;11(17):10609-22.

36. Eysenck G, Wilson G. How to measure personality. Moscow: "Kogito Center", 2012.

37. Goloshumova GS, Albakova ZA-M, Marchev KV, Kidinov AV, Gustova EA, Salakhova VB, Krasheninnikova NA. The interrelation of environmental and social factors and man's mental health. Ekoloji, 2019;28(107):6013-6.

38. Salakhova VB, Ovsyanik OA, Shmeleva NB, Lvova EN, Shabanova OV. The Problem of Higher Education in the Executive System of Russian Government. International journal of environmental \& science education, 2016;11(4):9883-9.

39. Masalimova AR, Mikhaylovsky MN, Grinenko AV, Smirnova ME, Andryushchenko LB, Kochkina MA, Kochetkov IG. The interrelation between cognitive styles and copying strategies among student youth. Eurasia Journal of Mathematics, Science and Technology Education, 2019;15(4):em1695. https://doi.org/10.29333/ejmste/103565

40. Babieva NS, Grinenko AV, Shulga TI, Tkhugo MM, Zotova LE, Shukshina LV, Ishkov AD. A Psychological Resource of Personality as an Integral Eco-Psychological Characteristic (The Interrelationship of Personal Development and Quality of Human Life). Ekoloji, 2019;28(107):629-35.

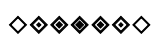

http://www.ejgm.co.uk 